\title{
Determining a Commuters' Exposure to Particle and Noise Pollution on Double-decker Buses
}

Aerosol and Air Quality Research

\section{OPEN ACCESS}

Received: July 15, 2021

Revised: September 28, 2021

Accepted: October 4, 2021

\section{${ }^{*}$ Corresponding Authors: \\ Erik Velasco \\ evelasco@mce2.org \\ Elvagris Segovia \\ geoelvse@nus.edu.sg}

\section{Publisher:}

Taiwan Association for Aerosol Research

ISSN: $1680-8584$ print

ISSN: 2071-1409 online

cc) Copyright: The Author(s). This is an open access article distributed under the terms of the Creative Commons Attribution License (CC BY 4.0), which permits unrestricted use, distribution, and reproduction in any medium, provided the original author and source are cited.

\author{
Erik Velasco ${ }^{1 *}$, Elvagris Segovia ${ }^{2 *}$ \\ ${ }^{1}$ Independent Research Scientist, 118719, Singapore \\ 2 Department of Geography, National University of Singapore, 117568, Singapore
}

\section{ABSTRACT}

This study evaluates a passenger's exposure to particles and noise on Singapore's doubledecker buses when choosing to travel on the upper or lower deck. Clean and calm journeys are vital to make public buses a choice mode of transport. In the case of Singapore, as in many other cities, double-deckers are in common use and comprise a large fraction of the total public transport ridership. Exposure to noise levels and concentrations of fine particles $\left(P M_{2.5}\right)$, equivalent black carbon (eBC) and number of particles (as a proxy of ultrafine particles, UFP) were simultaneously measured on both decks. Concentrations of particle-bound polycyclic hydrocarbons and particles' active surface area were also measured to investigate the combustion fingerprint of the particles and their average size. Concentrations of $\mathrm{PM}_{2.5}$ on the upper deck exceeded up to $50 \%\left(18 \mu \mathrm{g} \mathrm{m}^{-3}\right)$ those on the lower deck. Concentrations of eBC were higher on the upper deck up to $12 \%\left(0.6 \mu \mathrm{g} \mathrm{m}^{-3}\right)$, but on occasions were $40 \%\left(0.9 \mu \mathrm{g} \mathrm{m}^{-3}\right)$ lower. In contrast, UFP often measured in slightly higher concentrations $\left(\sim 8 \%, 1000 \mathrm{\#} \mathrm{cm}^{-3}\right)$ on the lower deck. Noise levels were always $\sim 5 \mathrm{dBA}$ higher downstairs. Particle loads responded to the intake of outdoor air by the air conditioning system, while sharp increases were observed on both decks every time the doors were opened to pick up and drop off passengers. In the case of the assessed route, which started and ended in fully enclosed terminals, the infiltration of particles emitted by arriving and departing buses contributed critically to the loads of $\mathrm{PM}_{2.5}$ on the upper deck. Improvements in the ventilation system on both decks, changes in engine operation at bus terminals, and faster boarding at bus stops through better coordination of bus services will reduce the load of particles to which passengers are exposed on double-decker buses.

Keywords: Urban transport pollution, Personal exposure, Public buses, Ultrafine particles, $\mathrm{PM}_{2.5}$

\section{INTRODUCTION}

Double-decker buses are widely used for public mass transport in many cities around the world not only because of their large seating capacity, but also due to their shorter length that allows for easy operation through narrow streets and tight corners (Hancock and Woodcock, 1988; Vuchic, 2002).

Commuters usually choose the upper deck for longer trips, while preferring to remain in the lower deck for shorter rides, thus avoiding climbing stairs and rushing down for alighting (Sun et al., 2014). This is particularly true for senior commuters, who sometimes claim that struggling up the stairs causes them to feel dizzy, which has been proved by assessments of the ability of passengers to maintain balance inside moving buses (Turner and Griffin, 1999; Kerekla and Tyler, 2019).

Passengers choosing to stay on the lower deck may experience higher loads of road traffic pollution when doors open. However, poor ventilation may cause an accumulation of pollutants in the upper deck, which makes staying downstairs more advisable. Similarly, with no driver guarding the upper deck, commuters tend to be louder and more raucous when they are out of earshot. Hence, sitting downstairs may be more pleasant. 
To find out whether or not passengers sitting on the upper deck are exposed to less traffic pollution and experience calmer trips, we evaluated and compared the characteristics and concentration of particles, as well as noise levels on both the upper and lower decks of doubledecker buses in Singapore. We focused on particles and not on gaseous pollutants such as carbon monoxide (CO) and nitrogen dioxide $\left(\mathrm{NO}_{2}\right)$, which are also toxic species embedded in exhaust plumes, because studies suggest that adverse health effects are generally associated most strongly with particles (Knibbs et al., 2011, and references therein).

Double-decker buses are in common use throughout Singapore. They operate since 1977 (Menon and Kuang, 2006). Out of 5860 public buses plying the roads, around 50 per cent are double-decker buses. All of them are equipped with rear-mounted air conditioning units, while most are powered by diesel engines under Euro V or VI emission standards. It is important to point out that buses are the most widely used mode of public transport in Singapore, comprising 53 per cent of the total public transport ridership (LTA, 2020).

A previous study in Singapore reported higher concentrations of particles, especially of ultrafine particles ( $\leq 100 \mathrm{~nm}$ in size, UFP), inside buses than in a site not directly affected by traffic emissions, 25 and $21 \times 10^{3} \mathrm{\#} \mathrm{cm}^{-3}$, respectively; but lower than at bus stops and sidewalks along a busy road, 46 and $38 \times 10^{3} \mathrm{\#} \mathrm{cm}^{-3}$, respectively (Tan et al., 2017). The same study also found an increase in the load of particles when doors open and close to pick up passengers at bus stops, as it has also been reported elsewhere (e.g., Targino et al., 2017; Lim et al., 2015; Tsai et al., 2008). Assessing the concentration of particles to which commuters are exposed to inside buses is relevant because commuters are likely to experience exposure to a large proportion of air pollution during daily commuting trips (Kumar et al., 2018; de Nazelle et al., 2017; Cepeda et al., 2017; Knibbs et al., 2011).

Cross-sectional epidemiological studies have found that long-term exposure to both traffic noise and air pollution increases the risk of cardiovascular disease, hypertension, and mild cognitive impairment (e.g., Fucks et al., 2017; Tzivian et al., 2016; Kälsch et al., 2014; Beelen et al., 2009); while a controlled study found that short-exposure to diesel exhaust and traffic noise causes oxidative stress (Hemmingsen et al., 2015). Although a synergistic mechanism between both exposures has yet to be found, their independent impacts have been well documented, therefore noise and air pollution must be considered when assessing the risk to public health (Stansfeld, 2015).

To the best of our knowledge, no studies have previously evaluated a passenger's exposure to particle pollution and noise on both decks of double-decker buses simultaneously. Thus, the findings of this study should be of special interest to cities with an intense service of these type of public buses, such as London, Dublin, Hong Kong, and Singapore. Similarly, the results should also be useful for cities planning to introduce or expand the use double-decker buses like Cairo, Addis Ababa, Penang, and Vancouver, as well as in those in which they are part of fleets of Bus Rapid Transit (BRT) systems like Mexico City and Ottawa. The results of this study aim to provide information to achieve cleaner systems of public transport considering the health of the passengers a priority.

\section{METHODOLOGY}

Bus service 7 was selected for this study as it is a major trunk route bridging the east and west sides of Singapore (see Fig. SM3). It covers a route of $23 \mathrm{~km}$ in approximately $90-100 \mathrm{~min}$ with an operation frequency of $12 \mathrm{~min}$. It connects the residential states of Bedok and Clementi with many suburban areas and the city center, and passes along the iconic retail boulevard of Orchard Road and the shopping area of Bugis. Much of this route has been retained since the 1970s because of its high demand.

This route plies avenues of five- to eight-lane single- or double-carriageway with several intersections with minor and major roads. The speed limit of all vehicles is 50 or $60 \mathrm{~km} \mathrm{~h}^{-1}$ depending on the road. One lane of the road is dedicated to buses, and depending on the route's section, it may accommodate up to 15 bus services. The measurements were conducted around the evening rush hour (17-21 h), when traffic gets worse. In the most congested sections, like Orchard Road and Bugis area, between 1700 and 2400 vehicles per hour circulate at that time 
(Velasco and Tan, 2016; Tan et al., 2017). Private cars represent 65\% of Singapore's vehicular fleet, heavy and light good vehicles, and motorbikes account for $17 \%$ and $15 \%$, respectively, while taxis and buses less than $2 \%$ each. Diesel engines are mostly reserved for goods vehicles and buses, private cars run on gasoline, as well as half of the taxi fleet, while the rest of taxis are hybrid models combining a gasoline engine with an electric motor (Land Transport Authority, 2021). The large majority of diesel and gasoline vehicles meet at least the Euro IV emission standards, since 2018 all new vehicles have to meet the Euro VI emission standards, while motorcycles are tightened to Euro IV standards. The use of ultra-low sulfur free (10 ppm) diesel and gasoline is mandatory since 2017 (Singapore Attorney General's Chambers, 2019).

The route was covered 16 times within 8 days in March 2018 during the spring inter-monsoon season. No day of measurements was affected by rain, mostly cloudy skies and northeast winds were present during the sampling sessions, ambient temperature and relative humidity ranged between 27 and $31^{\circ} \mathrm{C}$, and $66-89 \%$, respectively, as reported by the local meteorological service (https://www.nea.gov.sg/weather). No particular event of local or transboundary air pollution was observed. Hourly mass concentrations of fine particles $\left(\leq 2.5 \mu \mathrm{m}\right.$ in size, $\left.\mathrm{PM}_{2.5}\right)$ between 10 and $20 \mu \mathrm{g} \mathrm{m}^{-3}$ were reported by the local air quality monitoring network at ambient level across the city (https://www.haze.gov.sg/). On regular days Singapore's particle pollution originates from local combustion sources with a major part related to vehicular traffic, and another associated with fresh secondary aerosols produced under the influence of shipping and industrial emission activities (Rivellini et al., 2020).

Measurements were limited to weekdays. On each day, two sets of measurements were conducted. We started recording the first set of measurements at the Clementi bus interchange around 17:00 $\mathrm{h}$ and stopped at the Bedok bus interchange $99 \pm 11$ min (geometric mean \pm 1 standard deviation) later. The second set of measurements were recorded following the opposite direction, starting around 19:30 $\mathrm{h}$ and finishing $86 \pm 5 \mathrm{~min}$ later. The first trip was longer than the second by 13 minutes on average due to worsening traffic during the peak of the evening rush hour.

\subsection{Instrumentation}

We measured in-situ the mass concentration of $\mathrm{PM}_{2.5}$ and equivalent black carbon $(\mathrm{eBC})$, as well as the particle number concentration (PN) and equivalent continuous sound level $\left(L_{\text {eq }}\right)$ in both decks using two sets of portable battery-operated sensors. The mass concentration of particle-bound polycyclic aromatic hydrocarbons (pPAHs) and the active surface area (ASA) of the particles were measured on alternate trips on each deck because we counted with only one set of sensors for measuring these two parameters. The particle number concentration and ASA were measured as a means to quantify UFP. In microenvironments affected by traffic emissions most of the particles are found in the ultrafine fraction (Morawska et al., 2008). The small size and chemical composition of these particles exacerbate the health risk they pose. In terms of toxicology, ASA is the metric that explains better the variability in pulmonary inflammation triggered by particle pollution (Schmid and Stoeger, 2016; Oberdöster et al., 2005), which is particularly true for UFP, since they represent the highest surface area per mass. Measurements of air temperature $(\mathrm{T})$ and relative humidity $(\mathrm{RH})$ were also included. Table 1 summarizes the characteristics of each instrument.

One set of instruments was operated by a researcher sitting on the upper deck, whilst a second researcher monitored the other set on the lower deck. The sensors were placed over seats in the middle sections of both decks, two rows behind the stairs on the upper deck, and one row after the exit door on the lower deck. The sensors' position within the cabin is apparently less important, at least when the bus is moving with the doors closed, as shown by a study in Germany that found that particle exposure is not affected by seat placement in modern and well-ventilated buses (Bauer et al., 2018). Both researchers took notes on the events on board as a reference for the data analysis.

All sensors were programmed for $1 \mathrm{~s}$ readings, with the exception of those measuring pPAHs and ASA, which were programmed for $10 \mathrm{~s}$ readings. Our previous studies of personal exposure on transport modes showed that such frequencies are needed to capture the variability that characterizes particle pollution and noise in microenvironments affected by vehicular traffic (Tan et al., 2017; Velasco et al., 2016, 2019). 


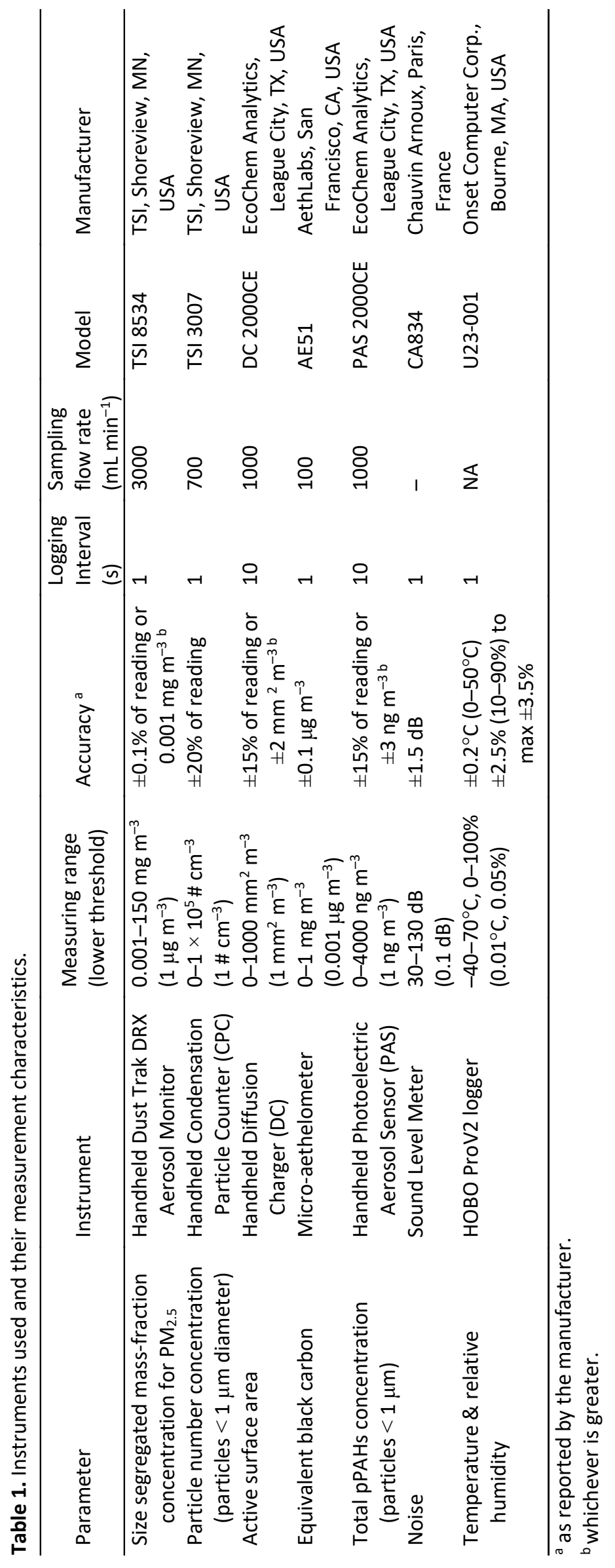


The instruments' configuration and preparation, as well as corrections applied and data postprocessing are described in the articles cited above. Details are provided in the Supplementary Material (SM). In previous studies, we evaluated the responses of the instruments for measuring $\mathrm{PM}_{2.5}$ and $\mathrm{eBC}$ against reference instrumentation, as a means of indirect calibrations. The pairs of instruments, including the sensors for monitoring particles, noise, $\mathrm{T}$ and $\mathrm{RH}$, were run side-byside for 5 minutes before and after each trip at locations not affected by traffic emissions outside the bus terminals. The mean differences between pairs of sensors during both testing periods were used to build linear regressions to remove any trends during the measurements and adjust the data sampled on both decks.

\subsection{Combustion Origin and Average Size of the Particles}

To gain further insight on the origin of the particles, the ratio obtained from the concurrent measurements of pPAHs and ASA was used as a fingerprint of the type of combustion particles (Bukowiecki et al., 2002). Following the acronyms of the instruments used to measure both metrics (Photoelectric Charger (PC) for measuring pPAHs, and Diffusion Charger (DC) for measuring ASA) the fingerprint is known as $P C / D C$ ratio. It depicts distinctive values according to the type of fuel and combustion. For instance, diesel exhaust particles yield ratios of $\sim 1 \mathrm{ng} \mathrm{mm}^{-2}$, while those from gasoline exhaust yield ratios $<0.6 \mathrm{ng} \mathrm{mm}^{-2}$ (Ott and Siegmann, 2006). Ratios of $>1 \mathrm{ng} \mathrm{mm}^{-2}$ are related to high emissions of pPAHs during periods of hard acceleration due to incomplete combustion (Tang et al., 2001). Particles from non-combustion sources or those that are already coated by condensable species such as semi-volatile hydrocarbons or molecules of water yield a PC/DC $\approx 0$.

Similarly, assuming spherical particles, the average size of traffic particles can be determined by the diameter of average surface $\left(D_{\text {Aver,S }}\right)$ as proposed by Kittelson et al. (2000) from the concurrent and independent measurements of PN concentration and ASA. $D_{\text {Aver, }}$ represents the diameter of a hypothetical monodisperse particle that has the same ASA as the measured polydisperse particle.

\section{RESULTS AND DISCUSSION}

The concentration of particles and noise level on both decks along the sampling trips were examined and compared first to those observed in previous studies in microenvironments affected by traffic emissions in Singapore. The main features of the particles along the trips were also analyzed in terms of the route and frequency of bus stops. Then, the concurrent measurements of ASA and pPAHs were used to investigate the combustion fingerprint of the particles, and the ASA and PN data to estimate the average size of the particles.

The Mood's median test and Kruskal-Wallis test were performed at 95 per cent confidence level $(p \leq 0.05)$ to evaluate and verify the significance of differences between decks with respect to concentrations of $\mathrm{PM}_{2.5}$, eBC and $\mathrm{PN}$, noise levels as well as $\mathrm{T}$ and $\mathrm{RH}$, respectively. The Anderson-Darling test showed that the observed variables were not normally distributed but positively skewed, hence the need to use nonparametric tests to investigate the equality of results obtained between decks.

The results presented here were obtained from more than 24 hours of sampling inside the buses, in which almost 90-thousand readings were collected for metrics measured every $1 \mathrm{~s}$ and 9 -thousand for metrics measured at every $10 \mathrm{~s}$. The readings collected during sixteen sampling sessions were expected to provide enough evidence on the difference in particle concentrations between both decks based on experiences from previous personal exposure studies on public transport (Tan et al., 2017; Velasco et al., 2019). As is the case in most field campaigns, practical choices had to be made to best meet the study objectives. A larger number of sampling sessions during more days would have allowed to collect more data and test other routes, thus providing more robust evidence, but field work expenses would have increased.

\subsection{Particle Concentrations and Main Features}

Fig. 1 shows the time series of $\mathrm{PM}_{2.5}, \mathrm{PN}, \mathrm{eBC}$ and noise measured simultaneously in the upper and lower decks during a representative sampling trip. The means and variabilities observed in each trip are presented in the SM (Tables SM1-SM11 and Fig. SM4). 

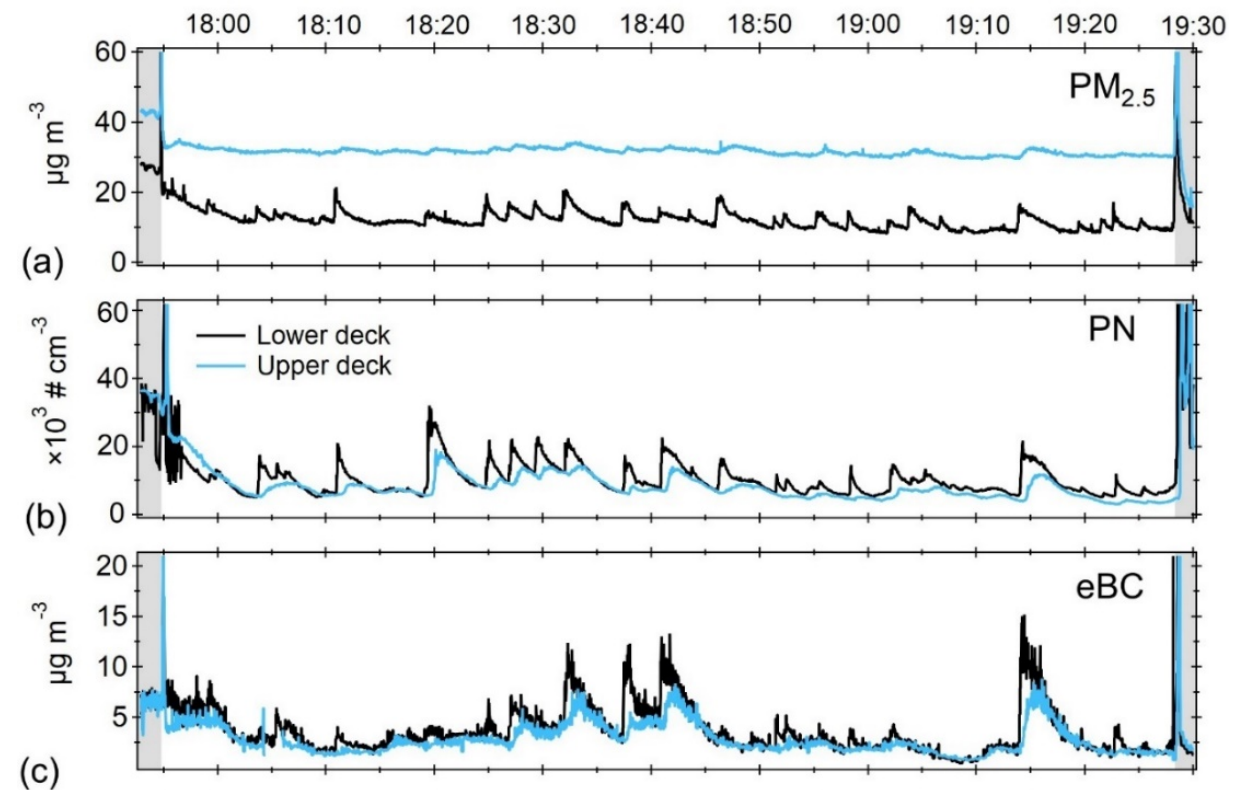

(c)

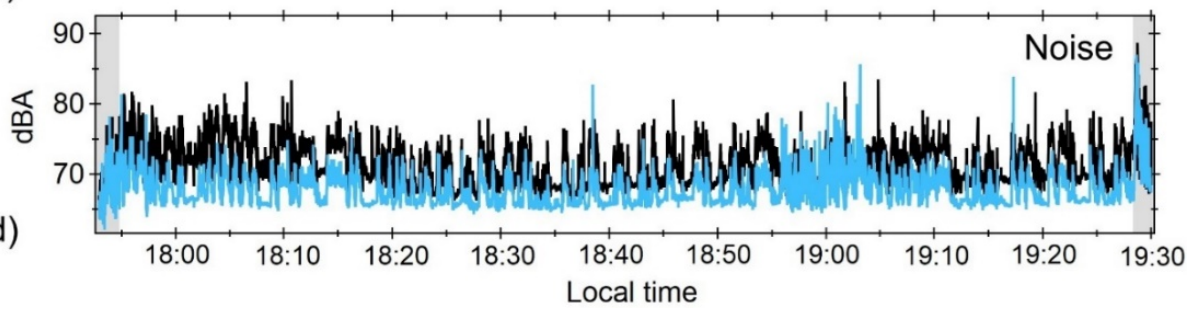

Fig. 1. Time series of mass concentration of $\mathrm{PM}_{2.5}$ and equivalent black carbon, particle number concentration and noise level measured on the upper (blue) and lower (black) decks during a representative sampling trip (6 Mar 2018). The shaded sections at the beginning and end of the trip correspond to the time spent at the boarding and alighting berths at the bus terminals.

Fig. 2 shows the difference in concentrations of $\mathrm{PM}_{2.5}, \mathrm{PN}$ and $\mathrm{eBC}$, noise levels, and $\mathrm{T}$ and $\mathrm{RH}$ measured simultaneously on both decks during each sampling trip. The differences were statistically significant for each individual trip for all measured variables, even though the variation between decks was minor on occasions, especially for $\mathrm{PN}, \mathrm{eBC}$ and $\mathrm{RH}$. There were not statistically significant differences in $\mathrm{PN}$ concentrations measured during one trip only.

We found that concentrations of $\mathrm{PM}_{2.5}$ were consistently higher on the upper deck. Concentrations of eBC were also higher on the upper deck, but less consistently. In contrast, concentrations of UFP were somewhat less abundant upstairs during most trips. Accounting for all trips, concentrations (median, $75^{\text {th }}-25^{\text {th }}$ percentiles, hereafter unless otherwise stated) of 35, 42-27 $(19,22-15) \mu \mathrm{g} \mathrm{m}^{-3}$ of $\mathrm{PM}_{2.5}$ were observed upstairs (downstairs). Similarly, mean concentrations of 5.2, 7.2-2.2 (4.6, 6.6-2.9) $\mu \mathrm{g} \mathrm{m}^{-3}$ of eBC, and 11.7, 17.4-7.0 (12.8, 16.2-8.1) $\times 10^{3} \mathrm{\#} \mathrm{cm}^{-3}$ of UFP were observed.

Although sharp increases were recorded on both decks every time the bus opened the doors to pick up and drop off passengers, these increases were more evident on the lower deck as shown in Fig. 1. Sharp increases in $\mathrm{PM}_{2.5}$ were hardly registered on the upper deck. However, such increases in PN and eBC (particle metrics strongly associated with vehicle exhaust) were always visible on both decks.

Contrary to increases in $\mathrm{PN}$, increases of eBC were expected to add up to a similar amount to $\mathrm{PM}_{2.5}$ mass concentration, but it was not always the case. As shown in Fig. 1, not all eBC peaks were reflected by $\mathrm{PM}_{2.5}$ peaks to the same extent. This anomaly may respond to inaccurate readings to fast changes in particle loads by the micro-aethelometer and DustTrak aerosol monitor used to measure $\mathrm{eBC}$ and $\mathrm{PM}_{2.5}$ mass concentrations, respectively. The former instrument is based on aerosol light absorption, and contributions from non-carbonaceous light-absorbing aerosol components like mineral dust, or non-black carbon light-absorbing carbonaceous matter (i.e., brown carbon) may affect its readings (Petzold, et al., 2013). Also note that the micro-aethalometer 


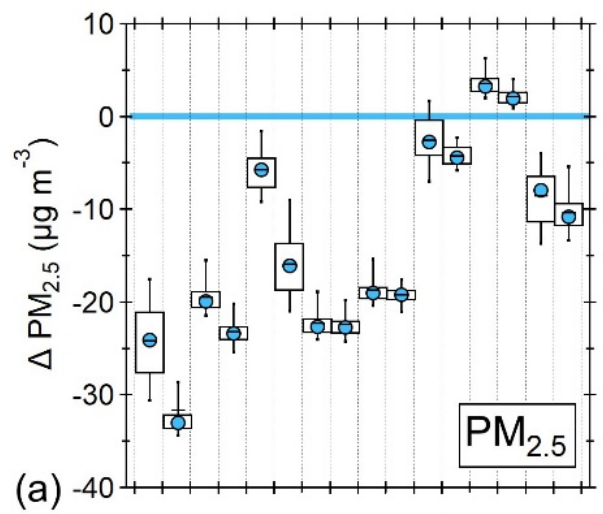

(a)
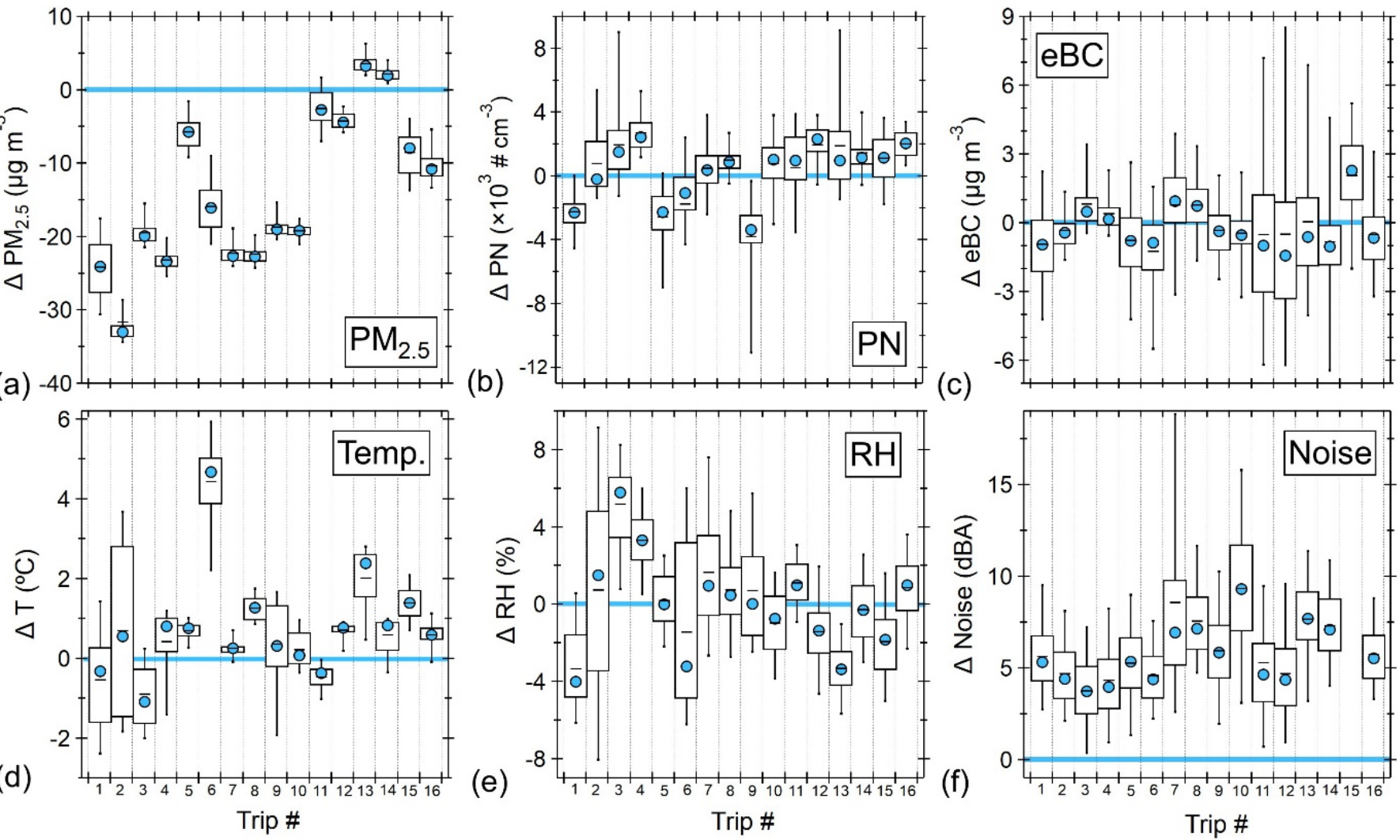

Fig. 2. Differences in concentrations of (a) $\mathrm{PM}_{2.5}$, (b) particle number, (c) equivalent black carbon, (d) temperature, (e) relative humidity, and (f) noise levels between the lower deck and upper deck (i.e., lower-upper) for each set of measurements. Records above zero (blue thick line) indicate higher concentrations or values in the lower deck, and the opposite is true for negative records. In each box the middle line, top and bottom are arithmetic means, upper and lower quartiles $\left(75^{\text {th }}\right.$ and $25^{\text {th }}$ percentiles), respectively. Blue dots indicate medians. Whiskers extend to the $95^{\text {th }}$ and $5^{\text {th }}$ percentiles.

can yield irregular peaks and negative values when sampling at a high frequency or at low concentrations. These spurious readings were corrected during data postprocessing as described in the SM, but they can still be wrong at times, especially when concentrations are particularly low. This issue represents a drawback to our study and must be considered when interpreting the results. Similarly, the $\mathrm{PM}_{2.5}$ monitor is based on aerosol light scattering, and temporal changes in particle properties such as size distribution and chemical composition may affect its readings (Zhang et al., 2018). Therefore, we caution that the absolute readings from both instruments should be observed carefully, especially during transition periods with drastic changes in aerosol abundance.

For the times series shown in Fig. 1, frequent stops along the commercial boulevard of Orchard Road and the city center (18:20-18:50 h) yielded particle peaks every $3-4$ min when the doors opened for periods of 40-60 $\mathrm{s}$ to pick up passengers. The number of commuters along these sections of the route was large enough to pack the lower deck with over 40 seated and standing passengers, and over 35 seated passengers on the upper deck. Several routes ply this sector of the city, and it is usual to find two or three buses queuing at each stop, whose emissions contribute to fill the cabin with polluted air.

The number of passengers and loads of UFP and $\mathrm{eBC}$ showed similar patterns along the entire trips, although correlations between them were modest $\left(r^{2}=0.25-0.28\right)$. More commuters means more time with doors open, and therefore a major infiltration of dirty air. This trend can be observed in the box plots of Fig. SM4 summarizing the statistics of each measured parameter, including number of commuters, for each trip.

Plumes from braking and accelerating cars are ubiquitous during the evening rush hour, contributing also to the particle loads inside buses, especially at bus stops next to traffic lights 
and road intersections (Tan et al., 2017). Going back to the time series shown in Fig. 1, the large particle peak registered at 19:15 h occurred in a bus stop next to a train station (Paya Lebar MRT station) and an eight-laned busy double-carriageway. Many passengers alighted at this stop and doors were kept open for no less than one minute, allowing dirty air to enter the bus.

Once the doors were opened, the particle loads peaked rapidly, reaching maximum concentrations within 10-35 seconds on the lower deck and 25-55 seconds upstairs based on the observations of the 16 trips. Particle peaks declined slowly during the next 5-7 minutes before returning to pre-peak concentrations on both decks. In cases of nearby stops (i.e., closer than 5 minutes), particle peaks did not return to pre-peak levels, and the infiltration of new polluted plumes built new peaks over already existing ones. Similar findings have been reported by other authors looking also into particle exposure inside single-decker buses (e.g., Tan et al., 2017; Targino et al., 2017; Lim et al., 2015; Tsai et al., 2008).

For the sampling trip shown in Fig. 1, the effect of frequent stops can be observed in the series of four consecutive peaks between 18:25 and 18:35 h. Although $\mathrm{PM}_{2.5}$ and eBC registered these peaks, the pattern was more evident in the case of UFP (i.e., PN). In cities with strong vehicular controls, the majority (>95\%) of traffic particles correspond to ultrafine aerosols (Morawska et al., 2008; Vu et al., 2015).

Taking as reference the time in which the loads of UFP increased rapidly after the doors were opened, and the associated changes in concentrations, we found that the plumes rich in fresh particles diluted by $65-90 \%$ on average once they reached the upper deck. However, on a few occasions, spikes up to 2 times larger were observed on the upper deck, maybe as a consequence of the internal flow within the cabin. The temporal increases in $\mathrm{PM}_{2.5}$, as already mentioned, were generally negligible on the upper deck.

No accumulation of particles was observed on either deck along the journeys. In contrast, a gradual decrease was consistently observed on both decks during a period of 10-20 min after leaving the bus terminals. Few and quick stops limited the infiltration of particles throughout the first section of the route in both directions. However, the infiltration of dirty air at the bus terminals was important, and resulted in high concentrations of particles during the first few minutes of the trips.

\subsection{Particle Infiltration in Bus Terminals}

The assessed route starts and ends in bus terminals fully enclosed within buildings serving as integrated transport hubs. Although drivers turn off the engine after parking the bus, doors are usually left open, and dirty air easily infiltrates the cabin in the $\sim 30$ minutes that the bus remains parked. The dirty and warm air in the terminal replaces the cool and less polluted air inside the bus. The vehicular concourse and parking areas are poorly ventilated, and the particles emitted by arriving and departing buses accumulate and pollute the interior of parked buses. Both terminals are always busy, one serving 14 different routes, and the other 26.

The infiltration of particles in accumulation mode $(50 \mathrm{~nm}-1 \mu \mathrm{m})$ apparently determines the loads of larger particles (i.e., $\mathrm{PM}_{2.5}$ ) to which commuters are exposed to along the entire trip on upper decks. These are carbonaceous particles directly produced in the engine that are subsequently coated with sulfate and semi-volatile organic species. They contribute largely in terms of mass rather than number. However, the larger number of particles emitted by diesel buses falls into the nucleation mode ( $<50 \mathrm{~nm}$ ) (Alam et al., 2016 and references therein). The smallest particles $(<10 \mathrm{~nm})$ form at elevated temperatures in the engine and tailpipe, and consist of highly nonvolatile material (Rönkkö and Timonen, 2019). The rest of nucleation mode particles are rapidly formed within the exhaust plume as combustion gases cool and condense, and consist mainly of volatile organic and sulfur containing compounds (Morawska et al., 2008). These particles coagulate rapidly with other particles, which favors the increase of larger particles, at the cost of reducing the total number of particles (Maricq, 2007). This process contributes to accumulate larger particles on the upper deck.

Although passenger concourses are air-conditioned and boarding and alighting berths are equipped with automatic sliding glass doors that open only when the bus reaches the berth, commuters are exposed to brief particle spikes while boarding and alighting. These spikes represent the highest particle loads to which passengers can be exposed during a terminal to terminal trip. 
Short-lived spikes (10-30 s) of $98 \pm 44 \times 10^{3} \#$ particles $\mathrm{cm}^{-3}, 66 \pm 28 \mu \mathrm{g} \mathrm{m}^{-3}$ of $\mathrm{PM}_{2.5}$ and $40 \pm$ $28 \mathrm{~g} \mathrm{~m}^{-3}$ of eBC (geometric mean \pm 1 standard deviation, hereafter unless otherwise stated) were observed, and represented concentrations amounting to 5-8, 9-20 and 3-8 times higher than those experienced at the passenger concourse, respectively.

\subsection{Infiltration of Outdoor Air}

After the initial stretch of trips, the lack of trend in the abundance of $\mathrm{PM}_{2.5}, \mathrm{eBC}$ and UFP on both decks suggests the infiltration of outdoor air by the air conditioning system (see Fig. 1). Such air dilutes temporal peaks caused by infiltration of dirty air at bus stops, and maintains relatively constant loads of particles.

We were not able to verify if the air conditioning systems were set to recirculation mode in the sampled buses. Setting the air-conditioning to recirculation mode on the lower deck would be useless due to constant infiltration of street air when doors were opened. On the other hand, such a setting may have served to clean the air inside the upper cabin. The null reduction or accumulation of particles after the initial stretches of the trips suggests that UFP and eBC concentrations inside the bus corresponded to those outside along the road. For the case of $\mathrm{PM}_{2.5}$, the concentrations on the lower deck must have corresponded to those outside, while those on the upper deck (which were consistently higher than those measured downstairs) corresponded to concentrations reached while the bus was parked in the enclosed terminals.

Conversely, whilst concentrations of $\mathrm{PM}_{2.5}$ on the lower deck were smaller than those measured at Singapore bus stops and along sidewalks of Orchard Road in previous studies ( $32 \pm 10$ and 36 $\pm 9 \mu \mathrm{g} \mathrm{m}^{-3}$, respectively) $\mathrm{PM}_{2.5}$ concentrations on the upper deck corresponded to such prior study measurements (Velasco and Tan, 2016; Tan et al., 2017). The concentrations of eBC on both decks were somewhat lower than those previously observed along sidewalks $\left(6.7 \pm 4.0 \mu \mathrm{g} \mathrm{m}^{-3}\right)$, and clearly lower than those at bus stops $\left(18.3 \pm 8.1 \mu \mathrm{g} \mathrm{m}^{-3}\right)$. For UFP, the number of particles was higher at bus stops and along sidewalks $\left(73.1 \pm 32.8 \times 10^{3}\right.$ and $44.0 \pm 6.1$ \# particles $\mathrm{cm}^{-3}$, respectively) than on both decks.

The higher concentrations of $\mathrm{PM}_{2.5}, \mathrm{eBC}$ and UFP reported along sidewalks and at bus stops in previous studies can be explained by the fleet modernization during the last five years. When such studies were carried out, public buses were already subject to Euro V emission standards, but it was still possible to find buses falling under Euro I, II and III emission standards.

We cannot explain why the differences in concentrations of $\mathrm{PM}_{2.5}$ were much larger than those of eBC and UFP between decks. Instead, we hypothesize that as a consequence of the design and operation of the air conditioning and ventilation system a small pressure difference develops between the decks in a matter of minutes at the beginning of a trip, which in turn hinders a vigorous exchange of air between them. It is also possible that the internal air flow, especially when the doors are open, limits the exchange of air between decks. The initial minutes of a trip with few and quick stops are apparently enough to mix the loads of UFP and eBC accumulated in the terminal, but not of larger particles (i.e., $\mathrm{PM}_{2.5}$ ). The infiltration of aged accumulation mode particles in enclosed terminals is apparently more critical than the infiltration of freshly emitted particles on the upper deck along the trip.

\subsection{Particle-bound Polycyclic Aromatic Hydrocarbons and Active Surface Area}

The measurements of pPAHs and ASA on both decks during alternate trips did not make it possible to determine differences in levels observed upstairs and downstairs. However, both metrics showed similar patterns to those observed for UFP and eBC. Correlations between ASA against PN and eBC were in general low $\left(r^{2}<0.20\right)$. However, moderate or strong correlations were observed for the case of pPAHs against both metrics $(0.20-0.98$, and $0.60-0.99$, respectively).

Polycyclic aromatic hydrocarbons are good tracers of vehicle exhaust particles. When the exhaust gases cool, aromatic species of four or more rings condense on the surface of existing aerosols, and form the so called pPAHs (Ravindra et al., 2008). Spikes over $300 \mathrm{ng} \mathrm{m}^{-3}$ of pPAHs were observed on both decks in phase with spikes of UFP and eBC. Considering the entire set of measurements, concentrations of $85,100-82(81,125-59) \mathrm{ng} \mathrm{m}^{-3}$ were recorded upstairs (downstairs). The higher variability downstairs responds to higher temporal increases when doors were opened. 
In traffic microenvironments, where particle burdens are dominated by UFP, high levels of ASA can be expected since such particle size fraction represents the highest surface area per mass of particles. Therefore, spikes over $350 \mathrm{~mm}^{2} \mathrm{~m}^{-3}$ in concert with spikes of pPAHs and UFP were often observed on both decks. Concentrations of 108, 130-91 $(127,148-112) \mathrm{mm}^{2} \mathrm{~m}^{-3}$ were recorded on the upper (lower) decks.

Similar to concentrations of $\mathrm{eBC}$ and number of particles, concentrations of pPAHs and ASA were in general lower on both decks than in bus stops and along the sidewalks of Orchard Road, as previously reported. In the case of pPAHs and ASA, mean concentrations of $225 \pm 84 \mathrm{ng} \mathrm{m}^{-3}$ and $172 \pm 68 \mathrm{~mm}^{2} \mathrm{~m}^{-3}$, respectively were measured at Singapore's bus stops, whilst measurements of $97 \pm 17 \mathrm{ng} \mathrm{m}^{-3}$ and $134 \pm 23 \mathrm{~mm}^{2} \mathrm{~m}^{-3}$, respectively were registered along Orchard Road's sidewalks (Velasco and Tan, 2016; Tan et al., 2017).

\subsection{Combustion Particles Fingerprint}

The PPAHs and ASA measurements on alternate trips yielded mean PC/DC ratios of $0.83 \pm 0.16$ on the upper deck and $0.77 \pm 0.28$ on the lower deck. The large variability and limited number of samples did not allow to determine a difference between decks. However, the ratios observed on both decks were similar to that observed along the sidewalks of Orchard Road (0.74), and substantially lower than those reported at bus stops (1.43) in our previous studies. This finding suggests that the intake of outdoor air by the air-conditioning system could have a greater influence on the load of UFP on both decks than the air that infiltrates every time the doors are opened. The PC/DC ratio on double-decker buses falls between those reported for exhaust plumes of gasoline and diesel vehicles, which is expected for measurements taken along the roads of Singapore (where all cars run on gasoline, and diesel consumption is limited to taxis, heavy duty vehicles and public buses).

\subsection{Average Size of Particles}

On average, particles of $52 \pm 9$ and $61 \pm 21 \mathrm{~nm}$ were observed on the upper and lower decks, respectively. Similar to the $\mathrm{PC} / \mathrm{DC}$ ratio, the number of samples taken were too small to determine a difference between decks, however the particle size was apparently more variable downstairs. The average size of particles fell into the higher range of the nucleation mode and the lower range of accumulation mode particles. As already explained, particles in the former mode are formed within the exhaust plume and tend to coagulate and condensate on larger particles, while accumulation mode particles are generated directly from the engine, and are mostly agglomerates of carbonaceous material (Morawska et al., 2008; Rönkkö and Timonen, 2019). Larger particles (i.e., $>1 \mu \mathrm{m}$ ) are primary emitted by mechanical abrasion processes, including wear emissions from brake linings, tires, and road pavement, as well as road dust resuspension (Thorpe and Harrison, 2008).

In our previous study at bus stops, the average size of particles ranged from 15 to $40 \mathrm{~nm}$ with a mean of $27 \mathrm{~nm}$, essentially the range reported for diesel particles from modern engines equipped with catalytic traps. The slightly larger $D_{\text {Aver, }}$ found in this study, suggests that the particles to which commuters are exposed on double-decker buses have already gone through a brief aging process resulting in an increased size. Moreno et al. (2021) used a miniaturized portable scanning mobility particle sizer to measure directly the particles' size distribution inside buses in Barcelona, Spain, also finding a size range $(35-50 \mathrm{~nm})$ representative of aged traffic particles.

\subsection{Noise Level}

In relation to noise, the sounds generated on the lower deck turned out to be louder. The equivalent continuous sound level along the entire trips was 66.7, 66.9-66.1 (71.8, 72.6-71.4) dBA upstairs (downstairs). The difference between decks was statistically significant (i.e., $p \leq$ 0.01). Instantaneous noise levels over $80 \mathrm{dBA}$ were scarce. Maximum readings of 70 (79) dBA were recorded in all sampling trips. No special trend was observed along the route. No substantial increases were recorded at bus stops. From the notes taken by the researchers about elevated or anomalous readings during the measurements, it was found that peaks responded merely to noisy people, especially passengers using their smartphones for watching videos or playing video games. 
The recorded noise level classifies as 'moderately annoying' by most scales of reference (e.g., Ouis, 2001), having a minor impact on people's mood during short periods of time. According to Singapore's legislation (NEA, 2020), the noise level on both decks was always below the maximum permitted $L_{\text {eq }}$ of $75 \mathrm{dBA}$ in commercial premises for periods no longer than 5 minutes. Notably, noise levels on the lower deck slightly exceeded the 12-h $L_{\text {eq }}$ of $65 \mathrm{dBA}$ legal limit imposed in residential areas during daytime, possibly posing a threat to the health of bus drivers, who work 8 to $10 \mathrm{~h}$ daily.

\subsection{Temperature and Humidity}

Slightly cooler temperatures were experienced on the upper deck. The constant infiltration of street air somewhat limits cooling downstairs. Temperatures of 23.7, 24.5-23.0 (24.9, 25.7$23.5)^{\circ} \mathrm{C}$ were recorded during the whole set of trips upstairs (downstairs). When leaving the bus terminal, both decks usually marked an equal temperature, but along the trip a slightly stronger gradual decrease was attained upstairs. Temperature drops of $4-6^{\circ} \mathrm{C}$ and $2-5^{\circ} \mathrm{C}$ were observed on the upper and lower decks, respectively. The cooling inside buses depends on the air-conditioning strength and the time the doors remain open while picking up passengers along the route.

During the final stretches of the trips, temperatures below $23^{\circ} \mathrm{C}$ were frequently recorded on the upper deck, and in two trips below $22^{\circ} \mathrm{C}$. Such temperatures contrast with the typical 28$31^{\circ} \mathrm{C}$ observed at bus stops in the evening (Velasco and Tan, 2016). The quick and drastic change in temperature when boarding a bus in the hot and humid climate of Singapore creates an unpleasant sensation (negative alliesthesia, de Dear, 2011) and ironically forces many commuters to carry sweaters with them.

Relative humidity ranged generally between $45 \%$ and $60 \%$ on both decks. Although significant differences were observed for individual trips, a mean humidity of $52 \pm 5 \%$ was found on both decks when considering all sampling trips. In our previous study, we reported a $\mathrm{RH}$ of $60-75 \%$ at bus stops. A similar RH was observed at both bus terminals in this study. Once on the bus, the RH decreased quickly, reaching values of $40-45 \%$ in $5 \pm 3$ minutes. Subsequently, RH levels fluctuated $50-60 \%$ during the rest of the trip. For sections with distant bus stops, increases of $~ 5 \%$ were often experienced.

\section{SUMMARY AND CONCLUSIONS}

Our study reveals that choosing to sit on the upper deck of a double decker bus would result in a more peaceful trip (i.e., lower levels of noise), but higher exposure to large particles (i.e., $\mathrm{PM}_{2.5}$ ). The opposite is true when choosing the lower deck. Consistent differences of 4-7 dBA and 15-20 $\mu \mathrm{g} \mathrm{m}^{-3}$ can be expected between decks.

With respect to ultrafine particles, lower concentrations are often found upstairs, but concentrations of equivalent black carbon can be higher there at times. However, there was little difference in the measurements for these two components of particle pollution between decks.

Although concentrations of $\mathrm{PM}_{2.5}$ observed on the upper deck fell within the range rated as normal by the local environmental authorities for 1 - $\mathrm{h}$ average ambient concentration $\left(<55 \mu \mathrm{g} \mathrm{m}^{-3}\right.$, https://www.haze.gov.sg/), it could be considered somewhat high compared to concentrations measured on buses in other cities with modern fleets (e.g., London, Hong Kong, Sacramento, see Fig. 6 in Velasco et al., 2019). However, $\mathrm{PM}_{2.5}$ concentrations on the lower deck, as well as those of ultrafine particles and equivalent black carbon on both decks are in the lower range of those reported for public buses in such cities.

Our results suggest that particle loads on double-decker buses respond to the intake of outdoor air by the air-conditioning system. Sharp increases on both decks can be expected every time the doors are opened to pick up and drop off passengers, especially in bus stops next to busy roads. In the case of the assessed route, which started and ended in terminals fully enclosed within buildings, the infiltration of particles emitted by arriving and departing buses contributed critically to the loads of $\mathrm{PM}_{2.5}$ on the upper deck. Keeping doors closed while buses are parked will prevent the accumulation of large particles on the upper deck, thus reducing their abundance on the next trip. 
In closing, commuters should choose the upper deck for calmer trips, but stay downstairs for cleaner trips.

\section{ACKNOWLEDGMENTS}

The field work for this study was supported by the National Research Foundation Singapore through the Singapore MIT Alliance for Research and Technology's CENSAM laboratory. CENSAM stopped activities and closed its doors on Dec. 2017. Data analysis and manuscript preparation were self-financed by the authors. The authors acknowledge the constructive comments of two anonymous reviewers and Armando Retama (Independent Research Scientist, Mexico), the editorial assistance of Nuraziah Binte Abdul Aziz (National University of Singapore, NUS), and financial support from the Department of Geography of NUS for the publication of the article.

\section{SUPPLEMENTARY MATERIAL}

Supplementary material for this article can be found in the online version at https://doi. $\operatorname{org} / 10.4209 /$ aaqr.210165

\section{REFERENCES}

Alam, M.S., Zeraati-Rezaei, S., Stark, C.P., Liang, Z., Xu, H., Harrison, R.M. (2016). The characterisation of diesel exhaust particles - composition, size distribution and partitioning. Faraday Discuss. 189, 69-84. https://doi.org/10.1039/C5FD00185D

Bauer, K., Bosker, T., Dirks, K.N., Behrens, P. (2018). The impact of seating location on black carbon exposure in public transit buses: Implications for vulnerable groups. Trans. Res. D Trans. Environ. 62, 577-583. https://doi.org/10.1016/j.trd.2018.04.009

Beelen, R., Hoek, G., Houthuijs, D., van den Brandt, P.A., Goldbohm, R.A., Fischer, P., Schouten, L.J., Armstrong, B., Brunekreef, B. (2009). The joint association of air pollution and noise from road traffic with cardiovascular mortality in a cohort study. Occup. Environ. Med. 66, 243-250. https://doi.org/10.1136/oem.2008.042358

Bukowiecki, N., Kittelson, D.B., Watts, W.F., Burtscher, H., Weingartner, E., Baltensperger, U. (2002). Real-time characterization of ultrafine and accumulation mode particles in ambient combustion aerosols. J. Aerosol Sci. 33, 1139-1154. https://doi.org/10.1016/S0021-8502(02)0 0063-0

Cepeda, M., Schoufour, J., Freak-Poli, R., Koolhaas, C.M., Dhana, K., Bramer, W.M., Franco, O.H. (2017). Levels of ambient air pollution according to mode of transport: A systematic review. Lancet Planet. Heath 2, 23-34. https://doi.org/10.1016/S2468-2667(16)30021-4

de Dear, R. (2011). Revisiting an old hypothesis of human thermal perception: Alliesthesia. Build. Res. Inf. 39, 108-117. https://doi.org/10.1080/09613218.2011.552269

Fuks, K.B., Weinmayr, G., Basagaña, X., Gruzieva, O., Hampel, R., Oftedal, B., Sørensen, M., Wolf, K., Aamodt, G., Aasvang, G.M., Aguilera, I., Becker, T., Beelen, R., Brunekreef, B., Caracciolo, B., Cyrys, J., Elosua, R., Eriksen, K.T., Foraster, M., Fratiglioni, L., et al. (2016). Long-term exposure to ambient air pollution and traffic noise and incident hypertension in seven cohorts of the European study of cohorts for air pollution effects (ESCAPE). Eur. Heart J. 38, 983-990. https://doi.org/10.1093/eurheartj/ehw413

Hancock, B.S., Woodcock, E.J. (1988). The history and design of double-deck buses and coaches. Int. J. Veh. Des. 9, 107-121. https://doi.org/10.1504/IJVD.1988.061509

Hemmingsen, J.G., Møller, P., Jantzen, K., Jönsson, B.A., Albin, M., Wierzbicka, A., Gudmundsson, A., Loft, S., Rissler, J. (2015). Controlled exposure to diesel exhaust and traffic noise - Effects on oxidative stress and activation in mononuclear blood cells. Mutat. Res. Fundam. Mol. Mech. Mutagen. 775, 66-71. https://doi.org/10.1016/j.mrfmmm.2015.03.009

Kälsch, H., Hennig, F., Moebus, S., Möhlenkamp, S., Dragano, N., Jakobs, H., Memmesheimer, M., Erbel, R., Jöckel, K.H., Hoffmann, B. (2014). Are air pollution and traffic noise independently associated with atherosclerosis: The Heinz Nixdorf Recall Study. Eur. Heart J. 35, 853-860. 
https://doi.org/10.1093/eurheartj/eht426

Karekla, X., Tyler, N. (2019). Reducing non-collision injuries aboard buses: Passenger balance whilst climbing the stairs. Safety Sci. 112, 152-161. https://doi.org/10.1016/j.ssci.2018.10.023

Kittelson, D., Johnson, J., Watts, W., Wei, Q., Drayton, M., Paulsen, D., Bukowiecki, N. (2020). Diesel aerosol sampling in the atmosphere. SAE Trans. 109, 2247-2254. https://www.jstor.org/ stable/44746018

Knibbs, L.D., Cole-Hunter, T., Morawska, L. (2011). A review of commuter exposure to ultrafine particles and its health effects. Atmos. Environ. 45, 2611-2622. https://doi.org/10.1016/j.atm osenv.2011.02.065

Kumar, P., Patton, A.P., Durant, J.L., Frey, H.C. (2018). A review of factors impacting exposure to $\mathrm{PM}_{2.5}$, ultrafine particles and black carbon in Asian transport microenvironments. Atmos. Environ. 187, 301-316. https://doi.org/10.1016/j.atmosenv.2018.05.046

Land Transport Authority (LTA) (2020). Annual Report 2018/2019. Government of Singapore, Singapore. https://www.lta.gov.sg/

Land Transport Authority (LTA) (2021). Annual Vehicle Statistics 2020. Government of Singapore, Singapore. https://www.Ita.gov.sg/

Lim, S., Dirks, K.N., Salmond, J.A., Xie, S. (2015). Determinants of spikes in ultrafine particle concentration whilst commuting by bus. Atmos. Environ. 112, 1-8. https://doi.org/10.1016/j. atmosenv.2015.04.025

Maricq, M.M. (2007). Chemical characterization of particulate emissions from diesel engines: A review. J. Aerosol Sci. 38, 1079-1118. https://doi.org/10.1016/j.jaerosci.2007.08.001

Menon, G., Kuang, L.C. (2006). Lessons from bus operation. Public Transport Council. Singapore. https://www.ptc.gov.sg/docs/default-source/publications-and-papers/lessonsfrombusoperat ionsrev5.pdf

Morawska, L., Ristovski, Z., Jayaratne, E.R., Keogh, D.U., Ling, X. (2008). Ambient nano and ultrafine particles from motor vehicle emissions: Characteristics, ambient processing and implications on human exposure. Atmos. Environ. 42, 8113-8138. https://doi.org/10.1016/j.at mosenv.2008.07.050

Moreno, T., Fernández-Iriarte, A., Amato, F., Moreno, N., Karanasiou, A., Querol, X., Duchaine, C. (2021). Urban Bus Air Quality: A technical guide. Institute of Environmental Assessment and Water Research. Barcelona, Spain. https://digital.csic.es/handle/10261/240220

National Environmental Agency (NEA) (2020). Noise Pollution. Singapore Government. https://www.nea.gov.sg/our-services/pollution-control/noise-pollution

Nazelle, A., Bode, O., Orjuela, J.P. (2017). Comparison of air pollution exposures in active vs. passive travel modes in Europe: A quantitative review. Environ. Int. 99, 151-160. https://doi.org/10.1016/j.envint.2016.12.023

Oberdörster, G., Oberdörster, E., Oberdörster, J. (2005). Nanotoxicology: An emerging discipline evolving from studies of ultrafine particles. Environ. Health Perspect. 113, 823-839. https://doi.org/10.1289/ehp.7339

Ott, W.R., Siegmann, H.C. (2006). Using multiple continuous fine particle monitors to characterize tobacco, incense, candle, cooking, wood burning, and vehicular sources in indoor, outdoor, and in-transit settings. Atmos. Environ. 40, 821-843. https://doi.org/10.1016/j.atmosenv.200 5.08.020

Ouis, D. (2001). Annoyance from road traffic noise: A review. J. Environ. Psychol. 21, 101-120. https://doi.org/10.1006/jevp.2000.0187

Petzold, A., Ogren, J.A., Fiebig, M., Laj, P., Li, S., Baltensperger, U., Holzer-Popp, T., Kinne, S., Pappalardo, G., Sugimoto, N., Wehrli, C. (2013). Recommendations for reporting "black carbon" measurements. Atmos. Chem. Phys. 13, 8365-8379. https://doi.org/10.5194/acp-138365-2013

Ravindra, K., Sokhi, R., Van Grieken, R. (2008). Atmospheric polycyclic hydrocarbons: Source attribution, emission factors and regulation. Atmos. Environ. 42, 2895-2921. https://doi.org/1 0.1016/j.atmosenv.2007.12.010

Rivellini, L.H., Adam, M.G., Kasthuriarachchi, N., Lee, A.K.Y. (2020). Characterization of carbonaceous aerosols in Singapore: Insight from black carbon fragments and trace metal ions detected by a soot particle aerosol mass spectrometer. Atmos. Chem. Phys. 20, 5977-5993. https://doi.org/10.5194/acp-20-5977-2020 
Rönkkö, T., Timonen, H. (2019). Overview of sources and characteristics of nanoparticles in urban traffic-influenced areas. J. Alzheimers Dis. 72, 15-28. https://doi.org/10.3233/JAD-190170

Schmid, O., Stoeger, T. (2016). Surface area is the biologically most effective dose metric for acute nanoparticle toxicity in the lung. J. Aerosol Sci. 99, 133-143. https://doi.org/10.1016/j.jaerosc i.2015.12.006

Singapore Attorney General's Chambers (SAGC) (2019). Road Traffic (Motor Vehicles, Construction and Use) Rules. https://sso.agc.gov.sg/SL/RTA1961-R9

Stansfeld, S.A. (2015). Noise effects on health in the context of air pollution exposure. Int. J. Environ. Res. Public Health 12, 12735-12760. https://doi.org/10.3390/ijerph121012735

Sun, L., Tirachini, A., Axhausen, K.W., Erath, A., Lee, D.H. (2014). Models of bus boarding and alighting dynamics. Transp. Res. Part A 69, 447-460. https://doi.org/10.1016/j.tra.2014.09.007

Tan, S.H., Roth, M., Velasco, E. (2017). Particle exposure and inhaled dose during commuting in Singapore. Atmos. Environ. 170, 245-258. https://doi.org/10.1016/j.atmosenv.2017.09.056

Tang, S., Johnson, R., Lanni, T., Webster, W. (2001). Monitoring of PM-bound polycyclic aromatic hydrocarbons from diesel vehicles by photoelectric aerosol sensor (PAS). SAE Technical Paper Series, No. 2001-01-3578. https://doi.org/10.4271/2001-01-3578

Targino, A.C., Rodrigues, M.V.C., Krecl, P., Cipoli, Y.A., Ribeiro, P.M. (2017). Commuter exposure to black carbon particles on diesel buses, on bicycles and on foot: A case study in a Brazilian city. Environ. Sci. Pollut. Res. 25, 1132-1146. https://doi.org/10.1007/s11356-017-0517-x

Thorpe, A., Harrison, R.M. (2008). Sources and properties of non-exhaust particulate matter from road traffic: A review. Sci. Total Environ. 400, 270-282. https://doi.org/10.1016/j.scitotenv.20 08.06.007

Tsai, D.H., Wu, Y.H., Chan, C.C. (2008). Comparisons of commuter's concentration to particulate matters while using different transportation modes. Sci. Total Environ. 405, 71-77. https://doi.org/10.1016/j.scitotenv.2008.06.016

Turner, M., Griffin, M.J. (1999). Motion sickness in public road transport: The effect of driver, route and vehicle. Ergonomics 42, 1646-1664. https://doi.org/10.1080/001401399184730

Tzivian, L., Dlugaj, M., Winkler, A., Weinmayr, G., Hennig, F., Fuks, K.B., Vossoughi, M., Schikowski, T., Weimar, C., Erbel, R., Jöckel, K.H., Moebus, S., Hoffmann, B. (2016). Long-term air pollution and traffic noise exposures and mild cognitive impairment in older adults: A crosssectional analysis of the Heinz Nixdorf recall study. Environ. Health Perspect. 124, 1361-1368. https://doi.org/10.1289/ehp.1509824

Velasco, E., Tan, S.H. (2016). Particle exposure while sitting at bus stops of hot and humid Singapore. Atmos. Environ. 142, 251-263. https://doi.org/10.1016/j.atmosenv.2016.07.054

Velasco, E., Retama, A., Segovia, E., Ramos, R. (2019). Particle exposure and inhaled dose while commuting by public transport in Mexico City. Atmos. Environ. 219, 117044. https://doi.org/1 0.1016/j.atmosenv.2019.117044

Vu, T., Delgado-Saborit, J. Harrison, R.M. (2015). Review: Particle number size distributions from seven major sources and implications for source apportionment studies. Atmos. Environ. 122, 114-132. https://doi.org/10.1016/j.atmosenv.2015.09.027

Vuchic, V.R. (2002). Urban Public Transportation Systems. University of Pennsylvania, Philadelphia, PA, USA.

Zhang, J., Marto, J.P., Schwab, J.J. (2018). Exploring the applicability and limitations of selected optical scattering instruments for PM mass measurement. Atmos. Meas. Tech. 11, 2995-3005. https://doi.org/10.5194/amt-11-2995-2018 